\title{
ATIVIDADE EPILINGUÍSTICA E O ENSINO DE LÍNGUA MATERNA: UM EXERCÍCIO COM A CONJUNÇÃO MAS
}

\begin{abstract}
Camila Arndt Wamser ${ }^{1}$
Letícia Marcondes Rezende ${ }^{2}$

\section{RESUMO}

O texto discute a importância do trabalho com a atividade epilinguística, entendida como a própria atividade de linguagem, no ensino de língua materna. O conceito de atividade epilinguística que adotamos é o da Teoria das Operações Predicativas e Enunciativas, elaborada pelo linguista francês Antoine Culioli. Com o intuito de delimitar o objeto de pesquisa e apresentar um modelo de atividade aplicado em sala de aula, trabalhamos com a conjunção adversativa mas, concebendo-a como marcador léxico-gramatical. O exercício foi aplicado a uma turma do sétimo ano da Escola Estadual Dr. Joaquim Batista, na cidade de Jaboticabal/SP. Como resultado do trabalho com a atividade epilinguística, os alunos tiveram condições de observar os mais variados contextos em que a marca aparece, bem como, compreender que as palavras não apresentam um significado estático. Além disso, esse trabalho permitiu aos alunos que construíssem seu próprio conhecimento e elaborassem uma gramática mais operacional e relevante.
\end{abstract}

Palavras-chave: Atividade epilinguística. Ensino de língua materna. Marca mas.

\section{INTRODUÇÃO}

Este texto é resultado de uma pesquisa de mestrado defendida em abril deste ano e trata do ensino de língua materna por meio das atividades epilinguísticas. Construímos uma ponte entre a Teoria das Operações Predicativas e Enunciativas, do linguista francês Antoine Culioli, e o ensino, pois esse quadro teórico não se dedica diretamente às questões relacionadas ao ensino e aprendizado da língua, porém seus conceitos e metodologias são muitos pertinentes nesse contexto.

Nossa prática foi movida pela constatação de que pouco se trabalha com a linguagem no ensino de língua, e, desse modo, não se levam em consideração partes importantes da elaboração, do amadurecimento e da organização do pensamento dos alunos. Ou seja, o foco do ensino, hoje, está na repetição de uma metalinguagem previamente definida pelo material didático utilizado nas aulas. Dessa forma, consideramos que o aprendizado da língua materna pode ser mais 
relevante se os próprios aprendizes forem responsáveis pela construção do seu conhecimento. Essa autonomia é conquistada por meio das atividades epilinguísticas.

Por defender o uso da atividade epilinguística no ensino de língua materna, colocamos a existência de uma variação radical de experiência, seja dos aprendizes, seja dos aprendizes e professor; mais do que isso, a assumimos como parte do processo de apropriação da língua. Essa postura diante da linguagem define-a como indeterminada e ambígua, o que garante ao sujeito um papel central na elaboração dos processos constitutivos da língua, principalmente na desambiguização dos enunciados. O entendimento dos enunciados dá-se pela sua desambiguização, uma operação de linguagem que movimenta os aspectos formais da língua e as experiências do indivíduo.

Nesse quadro teórico, assumir a importância do trabalho com a linguagem, com a atividade epilinguística, no ensino de língua, implica analisar os processos mais invariantes da língua, não apenas a descrição dos seus fatos.

Além de discussões sobre atividade epilinguística e o ensino de língua materna, este texto traz um modelo de atividade aplicada a uma turma do sétimo ano do ensino fundamental da escola Professor Doutor Joaquim Batista, na cidade de Jaboticabal/SP. Trata-se de uma aula na qual trabalhamos com os alunos os vários contextos em que a marca mas figura, priorizando o uso da oralidade, por meio de discussões e exposição do pensamento, na construção do conhecimento dos alunos.

\section{ATIVIDADE EPILINGUÍSTICA E O ENSINO DE LÍNGUA MATERNA}

Iniciamos a discussão acerca da importância da linguagem no ensino por meio de uma afirmação: não há trabalho com a linguagem no ensino de línguas. Isso porque ainda é utilizada uma prática de perpetuação do que seria a boa língua, ou seja, a transmissão das regras gramaticais. Até mesmo a produção textual, que deveria ser o momento da expressão metalinguística consciente, fica condicionada a esses parâmetros. Enquanto adotarmos, como professores, essa postura de repetidores da tradição gramatical e exigirmos dos alunos textos higienizados a ponto de não apresentarem autoria, apenas boas construções gramaticais, o ensino 
da língua materna não promoverá a apropriação da língua e da linguagem pelo indivíduo.

A importância do trabalho com o texto em sala de aula é muito clara em documentos oficiais, diretrizes e publicações ligadas ao ensino, que estipulam que o objetivo do ensino é formar indivíduos capazes de produzir textos coesos e coerentes. Ocorre que essa formação será bem sucedida quanto mais se manipular a linguagem, quanto mais se trabalhar o nível epilinguístico dos alunos. Esse processo formativo deve ser incrementado gradativamente, de forma que se torne, a cada série escolar, mais complexo. Entendemos que, justamente pela concepção de linguagem que adotamos, tal complexidade deve acompanhar o desenvolvimento psicossociológico do aluno Segundo Rezende (2010, p. 5), neste contexto "a gramática a ser ensinada será tanto melhor quanto mais ela contribuir para este grande objetivo da produção textual”.

Insistimos na ideia de que é nesse trabalho contínuo com o texto, também com a atividade epilinguística, que o sujeito modula suas representações das mais variadas formas. Rezende (2010) explica que esse processo permite aos seres, bem como às línguas, traçar sua trajetória evolutiva.

As modulações a que nos referimos, que também podemos chamar de atividade de equilibração ou regulação, acontecem norteadas pelas experiências, pelo empírico. Na sala de aula, muitas vezes esse aspecto é esquecido em favorecimento dos aspectos formais da produção. Ignorando os processos mentais internos sempre em construção no indivíduo que tem apenas uma aparente estabilidade e aceitando aquilo que está posto na forma da língua como estável, tirase do aprendiz a oportunidade de rever seus conceitos em outro momento, sob outro ponto vista, já que o certo ou o errado já foram marcados em seu texto com um número qualquer de zero a dez. Como as opiniões e formas de expressão não coincidem de indivíduo para indivíduo, incorrem nas dúbias noções de erro incrustadas no ensino e aprendizagem da língua materna. Sobre o erro, Rezende questiona:

Se valorizamos os processos construtivos que organizam as experiências singulares e colocamos a atividade do sujeito no centro desse processo, podemos avaliar o resultado e rotular de acerto ou erro? (REZENDE, 2010, p. 5). 
Utilizando ainda as ideias da autora, entendemos que o ser humano nunca está totalmente pronto, polarizado, ou está "entre" uma ou coisa e outra ou está "quase" algo. Assim também é com os enunciados da língua, que são parte constituinte de sua atividade psicológica e social. Para a autora, "trata-se de valorizar o estado de indiferença anterior ao verdadeiro e ao falso, ao positivo e ao negativo".

Os processos de estabilização e desestabilização de conceitos e ideias, que podem ser chamados de atividades epilinguísticas, abrem um gigante leque de oportunidades para o ensino. Além de ajudar a detectar os pontos da gramática com quais os alunos têm menos intimidade, o professor tem acesso à atividade criativa e criadora dos alunos, podendo a partir daí organizar suas aulas de modo mais dinâmico e próximo de suas realidades.

Quando defendemos o ensino de língua por meio das atividades epilinguísticas, estamos defendendo um ensino articulado com a linguagem, que implica abrir mão de trabalhar com o aluno ideal, e assumir a função de levar o aluno real a encarar a própria língua como propriedade sua. "O estudante deve perceber os mecanismos que ele próprio utiliza - independentemente da intervenção de pais ou professores - para compreender e formular enunciados do cotidiano" (SILVA, 2007, p. 21). Ainda, segundo a autora, é preciso levá-lo (o aluno) a rever sua relação com a língua que, desde muito cedo na escola, foi de adversidade, de inimizade, para passar a ser de propriedade, de liberdade.

Trazendo a atividade de linguagem para a sala de aula, é possível, a partir do material construído pelas línguas, abrir espaço para diversas formas de expressão linguística. Além de, validando as experiências e as contribuições dos alunos, conduzi-los a uma diferente visão do significado posto em contexto. Dessa forma, podemos falar em trabalho com respeito à variação.

Encontramos suporte para a defesa dessa metodologia nos PCNS:

A atividade mais importante [...] é a de criar situações em que os alunos possam operar a própria linguagem, construindo pouco a pouco, no curso dos vários anos de escolaridade, paradigmas próprios da fala de sua comunidade, colocando atenção sobre as condições e diferenças de formas e de usos linguísticos, levantando hipóteses sobre as condições contextuais e estruturais em que se dão. É a partir do que os alunos conseguem intuir nesse trabalho epilinguístico, tanto sobre os textos que produzem como sobre os textos que escutam e leem, que poderão falar sobre a linguagem, registrando e organizando essas intuições. (Brasil, 1999, p. 28). 
Como resultados, o mesmo texto aponta:

Os sujeitos se apropriam dos conteúdos, transformando-os em conhecimento próprio, por meio da ação sobre eles, mediada pela interação com o outro. Não é diferente do processo de aquisição e desenvolvimento da linguagem. [...] É na prática de reflexão sobre a língua e a linguagem que pode se dar a construção de instrumentos que permitirão ao sujeito o desenvolvimento da competência discursiva para falar, escutar, ler nas diversas situações de interação. (BRASIL, 1999, p. 33).

Assim estaríamos trabalhando com a linguagem no ensino de língua. Linguagem e língua são parte uma da outra, constituindo-se um todo, não indivisível, pois não se confundem, mas extremamente imbricado. De acordo com Culioli (1990), a língua e a linguagem, como duas instâncias, precisam estar muito claras, porém apenas temos acesso à segunda pelas marcas que essa deixa na primeira. Essa relação também precisa estar clara ao professor de língua, para que a ponte entre ambas seja feita.

Quando falamos de atividade de linguagem, referimo-nos também à atividade epilinguística, pois, como veremos a seguir, de acordo com a teoria em que se baseia este trabalho, os processos de produção e reconhecimento de textos que compõem a atividade da linguagem são intrinsecamente ligados aos processos formativos do discurso. Nesse lugar, encontram-se os arranjos léxico-gramaticais organizados a partir de um esforço anterior à verbalização - a atividade epilinguística.

$\mathrm{Na}$ prática do ensino de línguas, encontramos muito frequentemente atividades que priorizam as análises tidas como linguísticas e metalinguísticas. Cumpre-nos ressaltar que, nessa última modalidade, nem sempre os alunos têm o aproveitamento esperado, visto que a separação das atividades de léxico, gramática e produção textual dá a falsa impressão de que a língua é composta de partes independentes. Dessa forma, nenhuma reflexão do professor fica completa, deixando lacunas nos alunos, que tendem a aumentar com o passar dos anos escolares.

Possenti (2007, p. 92), quando nos diz que "aprender uma língua é aprender a dizer a mesma coisa de muitas formas", já adentra os domínios da atividade epilinguística, pois visa levar o aluno a manipular o texto de diversas maneiras e de forma consciente, numa já metalinguagem. Tais atividades não têm a necessidade de serem técnicas, mas significativas, de modo que a cada mudança do texto o 
aprendiz identifique os elementos que proporcionaram tal mudança, bem como os significados surgidos no texto.

As atividades epilinguísticas são as próprias operações de linguagem, que trabalham o material da expressão linguística por meio das escolhas do falante dentre as formas fornecidas pela língua. Essas escolhas referem-se à atividade de parafrasagem, que estabelece comparações e experimentações, na maioria das vezes inconscientes, e que sustentam a expressão linguística. São essas atividades que, quando praticadas continuamente, levam os alunos às atividades de análise metalinguística. Estas últimas, agora, conscientes e analisadas criticamente. O nível epilinguístico é alcançado apenas por meio do metalinguístico, cabendo ao professor ser/estar sensível às minúcias presentes nos enunciados dos alunos para, a partir delas, conduzir o conhecimento linguístico deles. Também cabe ao professor aceitar as variadas formas elaboradas pelos alunos e estar atento para perceber os momentos em que essa atividade está se manifestando para, então, trazer a reflexão do aluno para o nível da metalinguagem.

Segundo Franchi (1988), no trabalho com as atividades epilinguísticas, as classificações, morfológicas ou sintáticas são dispensáveis, assim o termo "gramática", remetendo a sistema e a ideia de uma metalinguagem representativa da nomenclatura gramatical, não tem espaço. Conhecer o sistema, sua nomenclatura e organização é função do professor que deve ser capaz de fazer a ponte entre o material linguístico trazido pelos alunos e a norma, fazendo multiplicar as formas de expressão das quais os alunos têm conhecimento. Segundo o autor citado acima, nem sempre se "trata de "aprender" novas formas de construção e transformação das expressões; muitas vezes se trata de tornar operacional e ativo um sistema ao qual o aluno já teve acesso fora da escola (p. 37)". Acreditamos que, por meio da sistematização, o aprendiz será capaz de incorporar novas formas linguísticas em seu repertório.

Geraldi (2002, p. 64) defende que "quem aprendeu a refletir sobre a linguagem é capaz de compreender uma gramática (...), aquele que nunca refletiu sobre a linguagem pode decorar uma gramática, mas jamais compreenderá seu sentido". O autor ainda alerta para o fato de que as atividades epilinguísticas são de extrema importância por tratar das aplicações que os falantes fazem das formas linguísticas, constituindo assim sua própria metalinguagem, e não de uma metalinguagem cristalizada pela reflexão de outros. 
A teoria culioliana apresenta uma proposta que traz para o ensino uma oportunidade da elaboração de um projeto pedagógico significativo e relevante de aprendizagem da língua materna. Um ensino/aprendizagem que se faça presente na vida dos alunos, não apenas na sala de aula durante a aula de gramática.

Atividades de reconstrução e transformação textual evidenciam os processos formativos presentes na base da produção linguística do indivíduo. A abordagem epilinguística propõe uma reflexão sobre o texto, trazendo as sutilezas da atividade de representação mental para o nível da metalinguagem.

As atividades epilinguísticas são aquelas que suspendem o desenvolvimento do tópico discursivo (ou do tema ou do assunto), para, no curso da interação comunicativa, tratar dos próprios recursos linguísticos que estão sendo utilizados, ou de aspectos da interação. (TRAVAGLIA, 2006, p. 34).

Travaglia (2006), citando Geraldi (1993, p. 24-25), exemplifica algumas situações em que é possível identificar tais atividades: hesitações, correções (auto ou heteroiniciadas), pausas longas, repetições, antecipações, lapsos, etc. Demonstramos abaixo alguns exemplos expostos pelo autor acima citado:

a) Achei o vestido de Maria lindo. Lindo não, maravilhoso.

b) Vamos fechar esta questão, pois o horário da reunião já acabou.

c) Agora quem vai dar sua opinião é o João.

d) Não creio que a palavra mansão dê uma boa ideia sobre como é a casa de Pedro, creio que palácio seria melhor, daria uma ideia mais exata da realidade.

e) Não creio que ele seja um... um... um...mentiroso.

f) Então ele trouxe o tou/o cavalo para o rodeio.

g) Me desculpe, mas você não pode usar esta linguagem dentro de uma igreja.

Ressaltamos, porém, que o conceito de atividade epilinguística que adotamos é mais complexo e amplo que o exposto pelo autor acima. Concebemos atividade epilinguística como a própria atividade da linguagem, manifestada por meio das marcas da língua, e operada exclusivamente pelo indivíduo, que é criativo e complexo.

A ideia de privilegiar o trabalho com o texto não incorre numa rejeição, ou inferiorização da gramática no ensino, trata-se justamente de um esforço por otimizar o ensino e a aprendizagem da língua.

Como consequência do ensino por meio das atividades epilinguísticas, chegamos a uma teoria gramatical consciente e operada exclusivamente pelos seus 
falantes, a atividade metalinguística. Isso proporciona, segundo Franchi (1988), um trabalho inteligente de sistematização gramatical. Podemos acrescentar ainda a habilidade de levantar hipóteses sobre a natureza da linguagem, do seu próprio discurso e das categorizações sintáticas.

Esse mesmo autor esclarece que não é possível saber quando, em que ano escolar os alunos terão essa consciência acerca da linguagem, mas nos dá o como fazer. Trata-se do resultado de uma intensa manipulação dos fatos da língua, com vistas a sistematizar um "saber linguístico" que o indivíduo (aluno) aprimorou e do qual se tornou consciente. O foco dessa prática é sempre a questão da significação, não apenas numa representação do mundo, mas também numa ação pela linguagem por meio e sobre os interlocutores, relacionando diretamente o modo e o estilo com que usamos seus múltiplos recursos de expressão.

Tendo em vista que o objetivo do ensino de língua é levar o aluno a trabalhar com qualidade no nível da metalinguagem, as atividades epilinguísticas garantem exatamente a base de sustentação para a realização de tal trabalho, pois tornam conscientes os elementos em uso, no seu aspecto funcional.

À luz dessas considerações sobre a linguagem, as atividades epilinguísticas e o ensino de língua materna, apresentamos a seguir um modelo didático para o trabalho com as atividades epilinguísticas em sala de aula.

\section{METODOLOGIA}

A atividade discutida a seguir foi trabalhada com uma turma de sétimo ano, na modalidade oral. Optamos pela oralidade por considerar que ela proporciona maior fluidez e liberdade ao discurso dos alunos. Esclarecemos que não se trata de uma discussão entre a oposição fala e escrita, mas da fala enquanto operação de linguagem.

Outro esclarecimento necessário diz respeito à escolha do tópico gramatical trabalhado com os alunos - a conjunção adversativa mas. Mais que uma escolha, o trabalho com o mas consiste numa delimitação da análise a que procedemos. A atividade epilinguística está presente em todos os enunciados da língua, dessa forma precisamos limitar nosso foco de atenção, para conferir maior rigor à pesquisa. 
O trabalho foi realizado com uma turma denominada $(A)$, no dia 24/05/2012. Nessa aula, os alunos trabalharam oralmente com enunciados em que figurava a marca mas. Com o auxílio da professora/pesquisadora foram levados a perceber características que diferenciavam e que aproximavam o valor semântico e sintático atribuído à marca em questão nos enunciados.

Utilizamos enunciados relacionados por meio da marca em questão retirados de algumas fábulas que haviam estudado em outros momentos; esses exemplos constituíam os contextos mais formais e explicitados pela gramática ensinada na escola. Outros enunciados representam contextos mais informais, não previstos pela norma. Dessa forma, e por meio do diálogo presente na aula, os alunos tiveram condições de construir o estatuto da marca mas, porém, compreendendo que os termos da língua não são estáticos.

Considerando os preceitos da atividade epilinguística, apresentamos os enunciados aos alunos e solicitamos que operassem substituições da marca, sugerissem continuações lógicas, reconhecessem pré-construtos e, acima de tudo, observassem e externassem as modificações de sentidos ocorridas em cada manipulação. Também solicitamos que agrupassem os enunciados de acordo com a função que exerciam, com a operação que desencadeavam.

O trabalho do professor, quando há opção pelo ensino por meio das atividades epilinguísticas, é de suma importância, pois cabe a ele conduzir o discurso dos alunos na construção do seu próprio conhecimento, sem, contudo, rotular seus comentários em certo ou errado. Desse modo, é possível tornar conscientes os processos epilinguísticos dos alunos, de modo a torná-los metalinguísticos.

Os contextos em que a marca é utilizada nos enunciados são variados e extrapolam as classificações apresentadas pela gramática escolar. Isso serve para ilustrar a ineficiência de basear o ensino da língua materna apenas nos conceitos e listas de classificações. Durante a aula, o conceito de conjunção não foi mencionado, pois nosso interesse estava nas operações desencadeadas pela marca mas, isso porém não impediu que tal conceito surgisse naturalmente nos comentários dos alunos, como veremos abaixo. 


\section{TRABALHO DOS ALUNOS COM OS ENUNCIADOS: UMA PROPOSTA DE ATIVIDADE EPILINGUÍSTICA}

Os alunos já conheciam os enunciados com os quais trabalhamos, pois eles foram selecionados em outras aulas com a turma, tanto que alguns enunciados foram retirados da fala deles próprios. Iniciamos a aula apresentando os enunciados um a um, de modo que os discentes pudessem comentar sobre cada um deles separadamente, mas, conforme a aula progredia, faziam pontes entre os enunciados aproximando-os e/ou distanciando-os.

Segue abaixo a ordem em que foram trabalhados os enunciados durante a atividade:

1. Mas que grande ideia eu tive!

2. Uma esponja, quando seca, é bem leve, pesa nada, mas, ao encher-se de água, fica muito mais pesada!

3. - Professora, mas o que é "folgada" mesmo?

4. Meus irmãos têm a vida atribulada, mas eu tenho uma vida folgada.

5. O burro preparou-se para cantar, mas conseguiu só zurrar.

6. Ele estava feliz, mas não estava satisfeito, ele queria mais alguma coisa.

7. Eram fardos muito grandes, só que bem mais leves que o sal.

8. Eu fico satisfeita porque fico feliz, mas também porque aprendi alguma coisa.

9. Canário cantar bem não é novidade, mas um burro ser cantor é mais que novidade!

10. Ele está atribulado no trabalho, mas não está cansado.

No decorrer da atividade, tentamos construir com os alunos o estatuto invariante da marca mas; isso se deu por meio das discussões, substituições e préconstrutos levantados pelos aprendizes.

A primeira característica observada pelos alunos quanto aos enunciados apresentados foi o distanciamento das ideias contidas neles. Esse distanciamento também pode ser chamado de complementaridade, fenômeno que implica a presença da negação, fator preponderante nos enunciados analisados. Dessa forma, os alunos foram questionados sobre a proximidade ou distanciamento dos termos "seca" e "molhada" no enunciado "Uma esponja quando seca é bem leve, pesa nada, mas ao encher-se de água fica muito mais pesada.". A tal questionamento responderam que são termos próximos semanticamente, se 
relacionados de alguma forma. Esse comentário ilustra um posicionamento extremamente competente diante da língua, pois, além da consciência de que os termos da língua precisam ser relacionados, há ainda a consciência de que a língua nos fornece inúmeras possibilidades de dizer. Com esse posicionamento, dão o primeiro passo para a construção de uma gramática própria, operada por eles próprios.

Trabalhando com o primeiro enunciado "Mas que grande ideia eu tive!", os alunos rapidamente perceberam o valor exclamativo da marca mas, propondo sua substituição por termos como "Nossa!" e "Ah!". Em seguida, levantaram préconstrutos que sustentariam o enunciado; nesse momento surgiu a negação de se ter uma grande ideia. Os alunos perceberam que, mesmo estando o burro pensando, ele não estava conseguindo ter ideias, pelo menos não grandes ideias. Assim, colocaram em jogo dois polos distintos: a ausência e a presença de grandes ideias. Essa alteridade (negação/afirmação) relacionada por meio da marca mas, é recorrente nos enunciados que alisamos com os alunos.

A aula ministrada com participação oral dos alunos é construída por eles, que sentem a própria responsabilidade buscando agilidade nas explicações, como podemos observar no comentário "É mais fácil a professora falar". Quando a professora tenta fazê-los lembrar de um termo que tinham visto há algum tempo.

Quando solicitados a substituírem o termo mas por porém no enunciado "Mas, que grande ideia eu tive!", os alunos prontamente verificaram a não equivalência desses termos, muitas vezes colocados como iguais (conjunções adversativas) pela gramática normativa. Um aluno sugeriu a forma "Porém, eu tive uma grande ideia", mas reconheceu que a atribuição da formalidade ao enunciado o impediria de ter a expressividade da exclamação no discurso direto. Tal mudança também foi percebida pelos alunos, que reconheceram a validade do enunciado parafraseado pelo colega, e a impossibilidade do uso de porém juntamente com a exclamação.

Iniciando o trabalho com o segundo enunciado "Uma esponja quando seca, é bem leve pesa nada, mas ao encher-se de água fica muito mais pesada", os alunos observaram que naquele contexto a substituição de mas por porém era uma possibilidade bastante viável. Além disso, perceberam que no enunciado estão em jogo duas propriedades estabilizadas do objeto esponja: a) Ser leve, quando, seca. b) Ser pesada, quando, molhada. Nas palavras do aluno: "Porque qualquer uma 
pode ficar seca ou molhada. Você compra ela seca depois você molha ela.". Tratando-se de uma mudança espaço-temporal.

Entre os enunciados 1 e 2 as crianças constataram uma diferença de sentido, sendo que no enunciado exclamativo a marca em questão é substituída por termos de ordem exclamativa; já no segundo a substituição é possível apenas por outro termo adversativo (porém). Vejamos a transcrição abaixo:

P.: Olhem bem, o que vocês disseram sobre esse MAS aqui [Mas que grande ideia eu tive!] que ele nem precisa estar aqui, e naquele [Uma esponja, quando seca, é bem leve, pesa nada, / mas, ao encher-se de água, fica muito mais pesada!] vocês disseram que ele tem que estar ali.

A.: Não é parecido.

A.: Se não tiver o MAS tem o PORÉM.

A.: Aí [Mas que grande ideia eu tive!] vai ter o mesmo sentido, mas aqui [Uma esponja, quando seca, é bem leve, pesa nada, / mas, ao encher-se de água, fica muito mais pesada!] tem que ter.

A.: Se não tiver nada aqui [Uma esponja, quando seca, é bem leve, pesa nada, / mas, ao encher-se de água, fica muito mais pesada!] muda o sentido da frase.

Com o enunciado (2), a relação do marcador mas com a negação também foi verificada pelos alunos. Foi apontado que <ser leve> e <ser pesada> são características opostas uma à outra. Os alunos, porém, rapidamente perceberam a proximidade, e possibilidade de coexistência, desses dois elementos expressandose por meio da máxima "Os opostos se atraem". Assim é construída a complementaridade das propriedades presentes no enunciado "Uma esponja seca, não é pesada, assim como, uma esponja molhada, não é leve".

Quando viram o enunciado de número três "Mas, o que é folgada mesmo?", os alunos comentaram que tinha o sentido mais parecido com o primeiro "Mas, que grande ideia eu tive!", porém, como justificativa deram apenas a posição do termo mas na frase, ou seja, no início. O trabalho epilinguístico dos alunos era intenso, num primeiro momento chegaram a argumentar impacientemente que, na realidade, ninguém começa uma pergunta dessa forma "Ninguém usa porém no começo da frase. Nem quando a gente vai falar com outra pessoa a gente diz porém". No entanto, em seguida, criaram pré-construtos que sustentavam essa forma, validando-a. Nesses pré-construtos os alunos resgataram a negação sustentada 
pelo enunciado "Alguém não entendeu alguma coisa", "Alguém falou pra ele: Você é folgado. Aí ele perguntou: Mas o que é folgado, mesmo?" "Mas, não sabia o que era".

Quando trabalhamos almejando acessar o nível epilinguístico dos alunos, temos a oportunidade de visualizar os esforços feitos por eles para a compreensão dos enunciados. Nesse momento, eles testavam outros conectores, para o enunciado "Meus irmãos têm a vida atribulada, mas eu tenho a vida folgada". Quando pensaram no porque, a estranheza foi prontamente percebida e rejeitada, porém surge a seguinte modalidade, sugerida por um dos alunos: "Se colocar o PORQUE fica em forma de pergunta: Meus irmãos têm a vida atribulada, por que eu tenho a vida folgada?", que, nesse caso, deveria ser grafado separadamente, pois trata-se de um pronome interrogativo, e não da conjunção, como havíamos previsto.

É interessante observar o processo de regulação intersubjetiva elaborado pelo aluno; provavelmente ele não se deu conta da diferença da grafia de um porque e outro, nem precisaria, pois na oralidade as diferenças gráficas e classificatórias deixam de existir. Vejamos que, mesmo se tratando do pronome interrogativo, a relação de causalidade atribuída à conjunção porque é construída na paráfrase do aluno alterando simplesmente a entonação do enunciado: Meus irmãos têm a vida atribulada, porque eu tenho a vida folgada. Sendo que a vida folgada do sujeito do enunciador eu é a causa da atribulação na vida dos irmãos. Essa construção deve também ter ocorrido ao aluno, porém o não reconhecimento do porque em enunciados que não elaborem um questionamento o fez operar uma interrogação com tal termo.

Esse exercício do aluno atribui uma modalização de dúvida ao enunciado apenas pela entonação, pois a sua compreensão é perfeitamente possível ancorada por essa marca.

Além das substituições, os alunos foram questionados sobre a informação que é implicitamente negada no enunciado: " $A$ vida atribulada", construindo de certa forma uma paráfrase do tipo "Meus irmãos têm a vida atribulada, mas eu não tenho a vida atribulada".

O próximo enunciado analisado com os alunos foi "O burrico preparou-se para cantar, mas conseguiu só zurrar". Nesse caso, o termo zurrar foi encarado como resultado da ação de preparar, porém, um resultado tanto negativo, que estabelece a relação de complementaridade entre as duas noções <cantar> e <zurrar>. De 
modo que "zurrar" figura como um "quase canto", um "canto muito ruim", um "não canto".

Até esse momento, os alunos haviam observado que a marca mas está relacionada a ideias contraditórias, opostas, excetuando o caso da interrogação (Mas, o que é folgada mesmo?) e da exclamação (Mas, que grande ideia eu tive!). Nessas ideias, ou termos, que estabelecem oposição há normalmente uma negação pré-construída, que pode facilmente ser encontrada por meio de paráfrases que remontem os pré-construtos que Ihe formam a base. Os alunos percorreram esse caminho sem muitos esforços, de maneira natural, o que lhes permitiu estar cada vez mais sensíveis às manipulações e conclusões propostas.

Isso fez com que, no enunciado "Ele estava feliz, mas não estava satisfeito", o fato de haver duas noções semelhantes semanticamente (feliz e satisfeito), chamasse a atenção dos alunos: "Podem ser parecidas só que ... é estranho". Nesse caso, os alunos observaram que estar feliz, mas não satisfeito indica que a felicidade não é completa, "Ele queria mais alguma coisa". Quando questionados sobre a falta de termos opostos, disseram que havia no enunciado "Um não", fazendo o papel de complementar. Assim, trata-se de feliz, não felicíssimo, não verdadeiramente feliz. Tanto que apontaram que a expressão "não satisfeito" poderia ser substituída por "insatisfeito", explicitando o complementar com a presença da negação como prefixo. Essa situação, aparentemente contraditória de se estar feliz, mas não satisfeito, é explicada por um dos alunos: "É como quando você está num lugar e está feliz, mas está com fome, aí fica insatisfeito".

No enunciado seguinte, "Eram fardos muito grandes, só que bem mais leves que o sal", os alunos anteciparam o final esperado para a primeira parte do enunciado (Eram fardos muito grandes), que seria "ser pesados". Por meio desse exercício, verificaram a inversão do sentido dos enunciados organizados pela marca mas. Essa inversão é fortemente marcada pela negação <eram fardos muito grandes, mas não eram pesados>. Nesse enunciado não aparece a marca mas, de modo que foi solicitado a eles que identificassem a expressão que tinha sua função. Sem dificuldades identificaram a expressão só que no lugar de mas.

O enunciado "Eu fico satisfeita porque fico feliz, mas também porque aprendi algo" causou muita estranheza nos alunos, mesmo tendo sido produzido oralmente por eles próprios: "Nada a ver essa frase”. 
Segundo os alunos, esse enunciado deveria ser organizado da seguinte maneira: "Eu fico feliz porque aprendi algo". Dessa forma, não conseguimos proliferar muito o significado da expressão mas também. Foram apenas sugeridas algumas substituições com porém, que foram rejeitadas pelos alunos.

Os dois últimos enunciados "Canário cantar bem não é novidade, mas um burro ser cantor é mais que novidade" e "Ele está atribulado no trabalho, mas não está cansado" foram vistos juntos.

Trabalhando com o termo novidade, os alunos verificaram o que é e o que não é uma novidade, movimentando o complementar do termo, ou seja, construíram os valores que não representam uma novidade, juntamente com os que representam.

$P$.: Por que canário cantar não é novidade?

A.: Porque todo canário canta.

$P .:$ E então por que um burro cantor é mais que novidade?

A.: Porque burro não canta.

Novidade é isso, e não é aquilo. No caso, canário cantar não é novidade, mas burro cantor é justamente porque burros não cantam, ou cantam muito mal. Os alunos observaram a presença de cantar, como medidor da definição de novidade, nos seus dois polos: cantar bem e cantar mal.

Quanto ao último enunciado, "Ele está atribulado no trabalho, mas não está cansado", foi possível verificar com os alunos a expectativa gerada pela primeira parte do enunciado e a sua quebra, a partir da marca mas. Conforme podemos observar na transcrição abaixo:

A.: Tem uma oposição entre atribulado e cansado

A.: Não tem. É "mas não está cansado".

P.: O que seria o mais lógico para esta primeira parte aqui? "Ele está atribulado no trabalho"

A.: "mas não está bem cansado"

P.: Esqueçam o MAS e o PORÉM, o resultado de estar atribulado, qual seria o resultado esperado?

A.: Cansado.

Analisando o material produzido durante a aula, pudemos perceber que os alunos verificaram que a marca mas tem na função de inversor, juntamente com a negação sustentada pelos pré-construtos e a negação explícita, suas características 
invariantes. Sendo que a inversão consiste na forma de negação do resultado esperado, assim, o que se mantém como invariante em todos os enunciados analisados é a forte relação da marca mas com a negação.

Além de todas as nuances das relações estabelecidas pelo marcador mas, a atividade epilinguística dos alunos permitiu que construíssem o conceito de conjunção, mesmo que tal termo não tenha sido mencionado nas aulas. Não era nosso objetivo apresentar categorizações de palavras, mas viabilizar a construção de uma metalinguagem consciente e relevante para os aprendizes. Trata-se de uma gramática operada pelos próprios alunos.

Encontramos o primeiro indício do processo de construção do conhecimento de tal conceito quando os alunos foram questionados sobre a possibilidade de se retirar o elemento conector do enunciado "Uma esponja quando seca é bem leve, pesa nada, mas ao encher-se de água fica muito mais pesada" e responderam que isso não seria possível "Por que fica faltando uma coisa no meio". Essa resposta sinaliza o reconhecimento da importância dos elementos conectores, que muitas vezes são elementos coesivos. A mesma percepção se repetiu quando estudaram o enunciado "Meus irmãos têm a vida atribulada, mas eu tenho a vida folgada" ("Nem dá para pronunciar sem nada no meio"). É claro que reconhecemos que também é possível a relação desses enunciados por meio de pausas, porém as pausas como mecanismos de relação de ideias são mais frequentes na oralidade. Percebemos que os alunos identificaram a impossibilidade da relação primeiramente por meio da escrita, pois apresentamos os enunciados no quadro-negro.

Retomando a construção do conceito de conjunção, vejamos a discussão do enunciado "O burro preparou-se para cantar, mas conseguia só zurrar", foi nesse momento que o conceito de conjunção, antes ensaiado, surgiu. Vejamos a seguir:

A.: O MAS é todas as palavras juntas então?

A.: Ele une as palavras.

A.: Não, assim os sentidos.

Mesmo sem o uso da terminologia e transferindo a ideia de conjunção apenas para o termo mas, a função de conector foi percebida e construída pelos alunos. A construção do conceito a partir das atividades epilinguísticas é mais significativa e operacional, já que surgiu de uma necessidade linguística reconhecida e experienciada pelos próprios alunos. Diferentemente do conceito pronto trazido pela gramática, que parte de uma definição e busca exemplos idealizados, que se 
encaixem perfeitamente, essa postura busca encurtar o caminho da experiência linguística dos alunos.

As conclusões às quais os alunos chegaram durante essa aula vão muito além da "matéria" trazida pelo livro didático e pela gramática, pensando apenas nos aspectos gramaticais da aula - os significados e funções da conjunção adversativa mas. O trabalho oral possibilitou aos alunos articular o léxico com a gramática e exercitar sua capacidade comunicativa, conferindo-Ihes mais autonomia diante da atividade de ensino à qual estavam expostos, bem como ao próprio processo de aprendizagem, que passa a ser de sua responsabilidade também. Trata-se da construção de uma gramática e de uma metalinguagem operada pelos próprios falantes da língua.

\section{CONSIDERAÇÕES FINAIS}

$\mathrm{Na}$ aula que descrevemos, observamos um melhor desenvolvimento linguístico da classe, bem como sua participação efetiva na construção e desenvolvimento da atividade. A atividade oral instaurou, na sala de aula, o diálogo entre professor e alunos e entre os alunos, criando um ambiente propício para a aprendizagem e desenvolvimento linguístico dos aprendizes. Também tornou possível identificar os pontos de maiores dúvidas dos alunos, e auxiliá-los nos ajustamentos necessários para as suas soluções. Assim eles construíam seu próprio aprendizado, que certamente terá um valor mais significativo e operacional.

Discutindo sobre os enunciados com a marca mas, os aprendizes perceberam a importância dela nos diferentes contextos apresentados, reconhecendo vários significados para a marca. O conceito de conjunção, explicitado pela gramática foi construído durante a aula, sem a necessidade da memorização de um conceito ou de uma classificação.

Como construtora do próprio conhecimento, a classe avaliou a qualidade e adequação dos enunciados que criava, rejeitando algumas formas e aceitando outras, num intenso processo de centralização e descentralização.

Um dos principais objetivos da nossa pesquisa é sugerir uma nova forma de se ensinar a língua. Desse modo, gostaríamos de ratificar a importância de se trabalhar com as atividades epilinguísticas. Porém, esclarecemos que não se trata de abandonar a norma e olhar apenas para os processos em uso nos enunciados; 
trata-se de, a partir da norma, ampliar a visão do aluno a ponto de torná-lo sensível para avaliar a pertinência de uma forma linguística ou de outra.

Vemos nas atividades epilinguísticas a oportunidade de renovar o ensino da língua materna, deixando de lado a pretensão de ensinar a língua para seus próprios falantes, e passar a ensinar os falantes a refletir sobre ela e usá-la de modo mais competente.

Propomos um trabalho que articule língua e linguagem, fazendo do livro didático um meio de levar o aluno a uma reflexão metalinguística relevante, e não a um fim em si mesmo. Um trabalho em que a oralidade, por meio de discussões e exposição do pensamento, seja uma ferramenta para o aprendizado da língua.

\title{
NOTAS
}

1 Possui Mestrado (2013) pela Unesp - Campus de Araraquara. A área de atuação é Ensino e Aprendizagem de Línguas. Possui também pós-graduação em Práticas Pedagógicas Interdisciplinares, com ênfase em Letramento e Alfabetização (2008) pelo Portal Faculdades e graduação em Letras pela Fundação Universidade do Contestado - Campus Caçador (2007), SC. Tem experiência na área de Letras, com ênfase em Língua Portuguesa.

${ }^{2}$ É professora titular da Faculdade de Ciências e Letras da UNESP, campus de Araraquara. Trabalha com a Prática de Ensino de língua materna (Português) e língua estrangeira (Francês) no Curso de graduação em Letras e está vinculada ao Departamento de Didática (área de educação). É também, desde 1987, professora do Programa de Pós-Graduação em Linguística e Língua Portuguesa da mesma Faculdade. Fez o seu doutorado na Universidade de Paris 7 (França) em 1980 e sua pesquisa está vinculada à Teoria das operações predicativas e enunciativas.

\section{ACTIVITÉ ÉPILINGUISTIQUE ET ENSEIGNEMENT DE LA LANGUE MATERNELLE : UN EXERCICE AVEC LA CONJONCTION MAS}

\begin{abstract}
RÉSUMÉ
Ce texte aborde l'importance de la recherche liée à l'activité épilinguistique, entendue comme l'activité propre du langage dans le cadre de l'enseignement de la langue maternelle. Le concept d'activité épilinguistique adopté ici est celui de la Théorie des opérations prédicatives et énonciatives élaborée par le linguiste français Antoine Culioli. Dans le but de délimiter l'objet de la recherche et de présenter un modèle d'activité applicable en salle de classe, nous avons choisi d'étudier la conjonction de coordination et d'opposition mas (mais, en français), comprise comme un marqueur lexico-grammatical. L'exercice a été proposé à une classe de septième année (la $5^{\text {ème }}$ du système français) du collège d'État Dr. Joaquim Batista, dans la ville de Jaboticabal, au Brésil. Dans le cadre de ce travail sur l'activité épilinguistique, les apprenants ont eu l'opportunité d'observer les divers contextes d'occurrence de ce marqueur, mais aussi de comprendre que les mots ne sont pas dotés d'une
\end{abstract}


signification statique. En outre, ce travail a permis aux apprenants de construire leur propre connaissance et d'élaborer une grammaire plus opérationnelle et pertinente.

Mots-clés: Activité épilinguistique. Enseignement de langue maternelle. Marqueur mas.

\section{REFERÊNCIAS}

BRASIL. Parâmetros curriculares nacionais: ensino médio. Brasília: MEC, 1999.

CULIOLI, A. Pour une linguistique de l'énonciation: opérations et représentations. Paris: Ophrys, 1990.

FRANCHI, C. Criatividade e gramática. São Paulo: Secretaria da Educação. Coordenadoria de Estudos e Normas Pedagógicas, 1988.

GERALDI, J. W. Linguagem e ensino: exercícios de militância e divulgação. Campinas: Meracdo de Letras, 2002.

POSSENTI, S. Por que (não) ensinar gramática na escola. 17. ed. Campinas: Mercado de letras - Associação de leitura do Brasil, 2007.

REZENDE, L. M. A indeterminação da linguagem e o conceito de atividade no ensino de língua materna. Estudos Linguísticos, São Paulo, v. 40, n. 2, p. 707-714. Disponível em: <http://www.gel.org.br/estudoslinguisticos/volumes/40/el.2011_v2_t20.red6.pdf>. Acesso em: 20 jun. 2013.

SILVA, A. C. S. A marca "porque" nos textos escolares: uma proposta para atividades epilingüísticas. 2007. 182 f. Tese (Doutorado em Linguística e Língua Portuguesa - Curso de Pós-Graduação em Linguística e Língua Portuguesa) Universidade Estadual Paulista, Faculdade de Ciências e Letras, Araraquara, 2007.

TRAVAGLIA, L. C. Gramática e interação: uma proposta para o ensino de gramática. São Paulo: Cortez, 2006. 